ADALAH : Buletin Hukum \&

Keadilan

\title{
Resistensi Umat Terhadap Ancaman Ekonomi Global Melalui Penerapan Prinsip Ekonomi Syariah
}

Syarifah Gustiawati Mukri

$\mathrm{Di}_{\mathrm{i}}$ mata Internasional Indonesia memiliki potensi dan peluang yang besar untuk mengembangkan potensi keuangan syariah secara global, kekuatan tersebut diakui karena Indonesia mayoritas penduduknya beragama Islam. Tak heran bila kemudian Indonesia termasuk ke dalam Top 10 Islamic Finance Assets (\$ Million) dan menempati urutan ke 9 dengan asset 35,626, sedangkan Malaysia di posisi peringkat 1 dengan total asset 423,285, bersumber dari catatan Islamic Finance Islamic Development Report. Indonesia juga telah diakui secara Internasional oleh UAE, Arab Saudi, Malaysia, dan Bahrain dengan posisi to offer lesson kepada negara lain di dunia untuk pengembangan keuangan syariah. Selain itu, pengakuan negara Qatar, Saudi Arabia, Malaysia, UAE, yang tergabung dalam (QISMUT) Indonesia dianggap sebagai kekuatan pendorong keuangan syariah di masa depan (OJK, 2015-2019: 108).

Hadirnya sistem ekonomi syariah diharapkan dapat mengakomodir kebutuhan masyarakat secara individu dan kolektif tanpa membedakan ras, suku, agama seseorang, sehingga dapat bersaing di era global. Dengan menghasilkan produk syariah yang tidak terbatas, serta menjamin keuntungan untuk masyarakat. Bahkan, mampu merespon transformasi ekonomi,

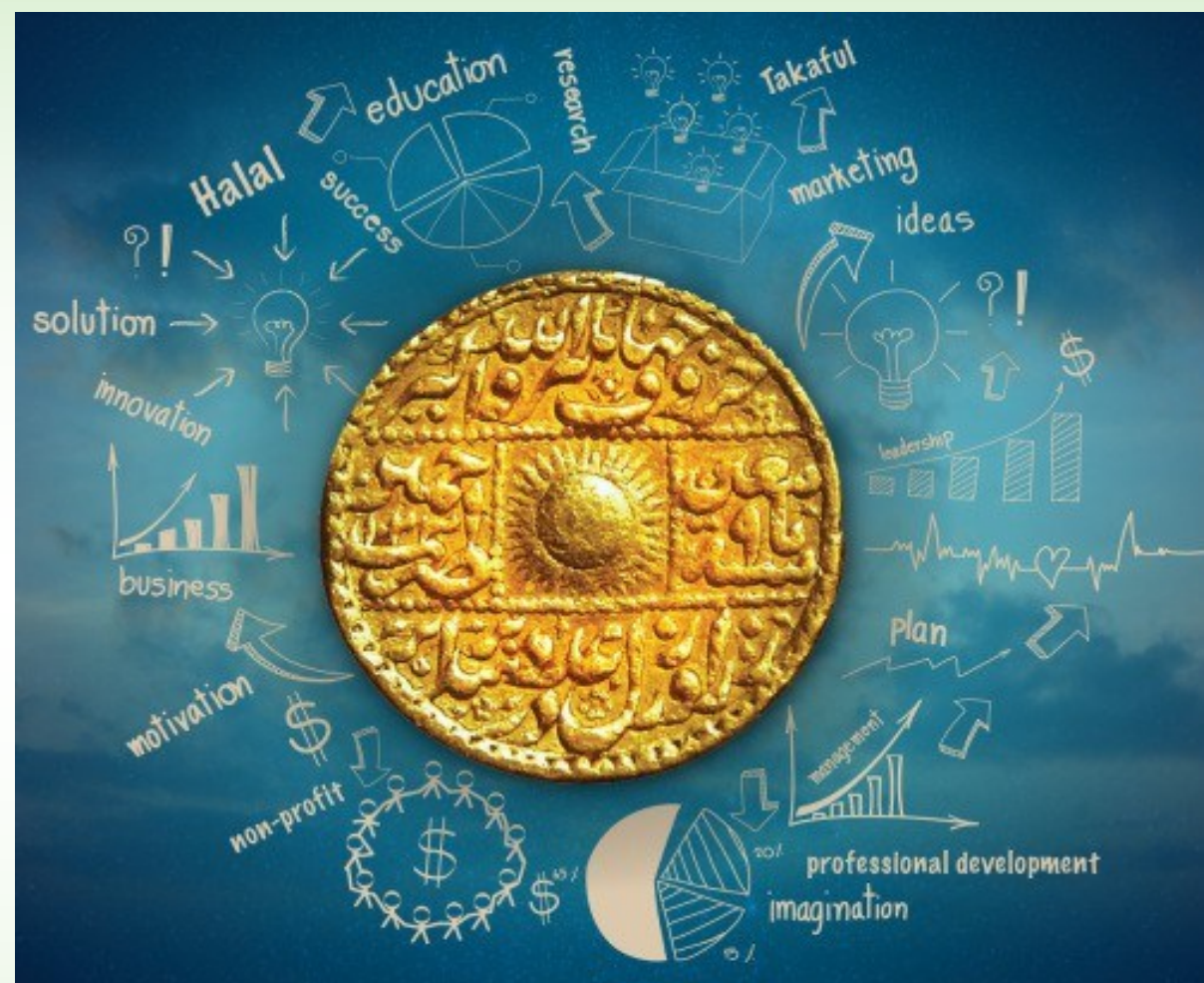

perkembangan ilmu pengetahuan dan teknologi, inovasi produk serta barang komoditas, yang diimbangi dengan kebutuhan masyarakat serta sesuai dengan prinsip-prinsip syariah agar tidak menyimpang kepada hal yang dilarang.

Alquran dan Hadis telah menjelaskan prinsip-prinsip syariah dalam setiap transaksi yang dilakukan hamba-Nya, sehingga terhindar dari keharaman dan praktik syubhat yang dilarang oleh agama. Prinsip tersebut berfungsi sebagai petunjuk manusia dalam setiap transaksinya. Aktualisasi ajaran Islam dalam praktik perbankan syariah haruslah memiliki komitmen terhadap prinsip dan moral agama yang bersumber dari Alquran dan Hadis, seperti menjunjung tinggi nilai kemaslahatan melalui praktik kejujuran dan keadilan di setiap kegiatan ekonomi (Najib, 2017: 55).

Prinsip-prinsip syariah yang harus dipegang teguh antara lain adalah: Pertama, Pelarangan Riba; Secara terminologis riba adalah kelebihan tanpa ada pengganti dan disyaratkan dalam transaksi jual beli (Sarkhasi, tth: 109). Artinya riba adalah pengambilan tambahan di atas pokok modal, yang dilarang Allah Swt. Sehingga riba diharamkan karena berdampak negatif terhadap individu, kolektif, bahkan berpengaruh dari sisi 
ekonomi. Secara individu riba menyebabkan sikap tamak dan mengambil hak milik orang lain dengan paksa. Karena dengan riba, orang yang meminjamkan uang meminta tambahan manfaat tanpa imbalan ganti.

Kedua, Gharar, secara bahasa adalah al-Khathru (Pertaruhan) (Sjahdeni, 2014: 169). Menurut UU No. 21 Tahun 2008 tentang Perbankan Syariah, gharar merupakan transaksi yang objeknya tidak jelas, tidak dimiliki, tidak diketahui keberadaanya, atau tidak dapat diserahkan pada saat transaksi dilakukan kecuali diatur lain dalam syariah. Gharar dilarang dalam prinsip Islam berdasarkan Hadis Rasulullah Saw, yang melarang jual beli al-Hashah (jual beli dengan cara lempar batu) dan jual beli gharar. Sistem gharar mengandung unsur memakan harta orang lain dengan cara yang batil. Gharar dilarang Islam karena adanya pertaruhan dan menimbulkan sikap permusuhan pada orang yang dirugikan (Taimiyah, tth: 22-23). Diantara praktek kontemporer yang mengandung gharar adalah short selling, yaitu suatu cara yang digunakan dalam penjualan saham yang belum dimiliki dengan harga tinggi dengan harapan akan membeli kembali pada saat harga turun (Fatwa DSN No. 80/DSN-MUI/III/2011).

Ketiga, Maisir. Maisir dalam istilah lain disebut qimar, artinya bertaruh dalam perjudian, artinya memperoleh sesuatu dengan mudah atau tanpa usaha. Sedangkan secara terminologis Maisir adalah setiap harta yang diperoleh dengan spekulasi (Sulami, 2008: 304). Menurut UU No. 21 Tahun 2008 tentang Perbankan Syariah, Maisir adalah transaksi yang digantungkan kepada suatu keadaan yang tidak pasti.

Keempat, Menghindari Produk yang diharamkan. Seperti menghindari produk minuman keras, babi, alat-alat musik yang dapat menjauhkan diri dari Allah, dan menghambur-hamburkan uang, serta hal-hal yang dapat merusak agama, akal, jiwa, harta, dan harga diri manusia.

Sistem Perekonomian berbasis syariah, bukan hanya sekedar alternatif dari perekonomian berbasis kapitalis, akan tetapi menjadi solusi atas kekurangan yang terdapat pada ekonomi kapitalis, sosialis dan komunis. Karena, ekonomi syariah mampu berkontribusi terhadap pengembangan ekonomi real, dengan aktualisasi prinsip syariah yang menjadi barometer nilai perekonomian dalam Islam. Prinsip keseimbangan antara nilai spiritual dan material, kebebasan berekonomi terpimpin, keseimbangan hak individu dan kolektif serta berorientasi pada kemaslahatan merupakan karakteristik ekonomi Islam, sehingga aktifitas ekonomi apapun yang dilakukan oleh masyarakat harus berorientasi pada kesejahteraan individu dan masyarakat.[]

\section{Pustaka Acuan:}

* Penulis merupakan dosen tetap bidang Pendidikan Ekonomi Syariah pada Fakultas Agama Islam UIKA Bogor.

Al-Sya'rowi, 'Aid Fadl, Al-Masyarif allslamiyah Dirosah Ilmiyah Fiqhiyah lilmumarosat Al-Amaliyah, th.

Fatwa DSN No. 80/DSN-MUI/III/2011 tentang penerapan prinsip syariah dalam mekanisme perdagangan efek bersifat ekuitas di pasar reguler Bursa Efek.

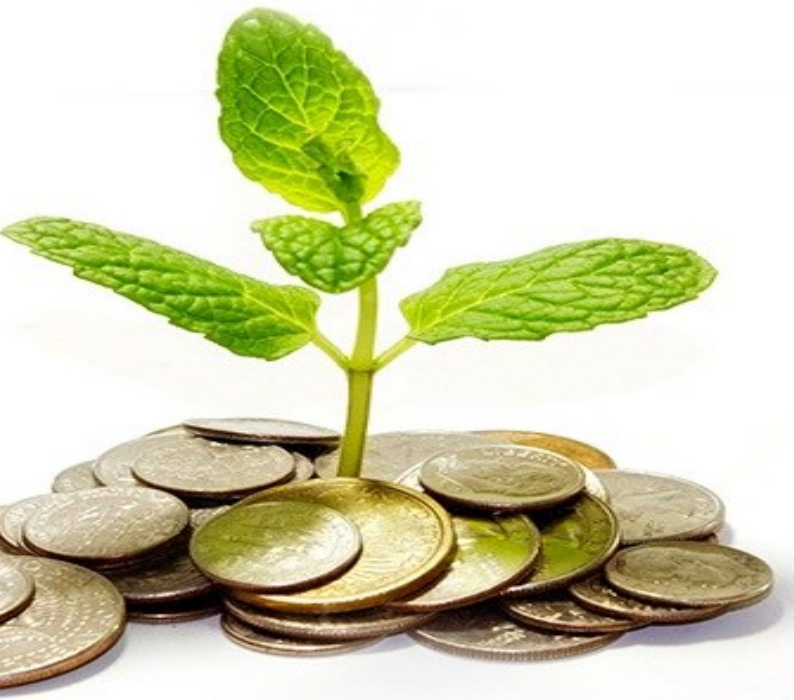

Najib, Muhammad Ainun, "Penguatan Prinsip Syariah Pada Produk Bank Syariah," Jurnal Jurisprudence, Vol.7 No. 1 Juni 2017.

Otoritas Jasa Keuangan. Modul Training of Trainers Keuangan Syariah, Roadmap Perbankan Syariah Indonesia, 2015-2019.

Sarkhasi, al-Mabshut, Beirut: Dar al-Ma'rifat, Vol. 12.

Sjahdeni, Sutan Remi, Perbankan syariah: Produk-produk dan aspek-aspek hukumnya, Jakarta; Kencana, 2014.

Sulami, Nasr Muhammad, Dhowabith Syar'iyah Lilististmar, Iskandariyah, Dar al-Iman, 2008.

Taimiyah, Ibnu, Kutub Wa Rasa'il wa fatawa Syeikhul Islam Ibnu Taimiyah, Kairo: Ibnu Taimiyah, Vol. 29.

'Adalah; Buletin Hukum dan Keadilan merupakan berkala ilmiah yang diterbitkan oleh Pusat Studi Konstitusi dan Legislasi Nasional (POSKO-LEGNAS), Fakultas Syariah dan Hukum UIN Syarif Hidayatullah Jakarta.

Penasehat: Prof. Dr. H. Abdul Ghani Abdullah, SH., Prof. Dr. H. A Salman Maggalatung, SH., MH. Pemimpin Redaktur: Indra Rahmatullah, Tim Redaktur: Nurrohim Yunus, Fathuddin, Mara Sutan Rambe, Muhammad Ishar Helmi, Erwin Hikmatiar. Penyunting: Latipah, Siti Nurhalimah. Setting \& Layout: Siti Romlah 